\title{
GW23-e0114 THREE-ITEM SCREENING FOR ANXIETY AND DEPRESSION IN CARDIAC OUTPATIENTS
}

doi:10.1136/heartjnl-2012-302920aa.2

Liao Jinmin, Sheng Li. Institute of Mental Health, Peking University

Objectives To evaluate the validity of a new screening tool (the three-item inventory) for anxiety and depression in cardiac outpatients.

Methods Fifty-four outpatients were collected by convenient sampling in the department of cardiology. During the waiting time, forty-six of them completed the three-item inventory with only three questions about sleepless, unexplained somatic symptoms and mood disturbance accordingly, and also HADS (hospital anxiety and depression scale) after oral consent. The specificity, sensitivity and other validity index were calculated.

Results According to the result of HADS, there were 16 cases with anxiety (34.8\%) and nine cases with depression (19.6\%). The sensitivity of the three-item inventory for anxiety was $88.0 \%$, specificity was $80 \%$, with PPV $80 \%$ and area under ROC 0.87 ; the sensitivity and specificity of it for depression were $78 \%$ and $65 \%$ respectively.

Conclusions The pilot study showed that the three-item inventory is good for anxiety screening, its validity for depression need further investigation for less depressive cases in the sample. 